\title{
Experimental Study on Antivibration Control of Electrical Power Steering Systems
}

\author{
Zhaojian Wang ${ }^{1}$ and Hamid Reza Karimi ${ }^{2}$ \\ ${ }^{1}$ State Key Laboratory of Automotive Simulation and Control, Jilin University, Changchun 130022, China \\ ${ }^{2}$ Department of Engineering, Faculty of Engineering and Science, University of Agder, 4878 Grimstad, Norway \\ Correspondence should be addressed to Zhaojian Wang; zhaojianwang1980@gmail.com
}

Received 7 May 2014; Accepted 9 May 2014; Published 10 June 2014

Academic Editor: M. Chadli

Copyright (c) 2014 Z. Wang and H. R. Karimi. This is an open access article distributed under the Creative Commons Attribution License, which permits unrestricted use, distribution, and reproduction in any medium, provided the original work is properly cited.

We focus on the antivibration controller design problem for electrical power steering (EPS) systems. The EPS system has significant advantages over the traditional hydraulic steering system. However, the improper motor controller design would lead to the steering wheel vibration. Therefore, it is necessary to investigate the antivibration control strategy. For the implementation study, we also present the motor driver design and the software design which is used to monitor the sensors and the control signal. Based on the investigation on the regular assistant algorithm, we summarize the difficulties and problems encountered by the regular algorithm. After that, in order to improve the performance of antivibration and the human-like steering feeling, we propose a new assistant strategy for the EPS. The experiment results of the bench test illustrate the effectiveness and flexibility of the proposed control strategy. Compared with the regular controller, the proposed antivibration control reduces the vibration of the steering wheel a lot.

\section{Introduction}

The electrical power steering (EPS) system has attracted a lot of attention in the past few years [1-3] due to the significant advantages over the traditional mechanical steering system. In the commercial market, the EPS system is also more and more in use for passenger cars. Compared with the traditional one, the EPS system can reduce the force exerted on the steering wheel by drivers, and the assistant force can vary according to the vehicle speed. Moreover, it has better dynamic characteristics, clearer road feel, and larger damping ratio to attenuate the high-frequency disturbance from the road $[1,4,5]$. Moreover, the EPS system can reduce the vehicle $\mathrm{CO}_{2}$ emissions and it is possible to use the EPS motor torque for advanced driver assistance systems.

The main tasks of the EPS system include the following: (1) providing an extra steering torque to the driver's steering torque and (2) giving the driver an adequate steering feel. The main principle of the EPS system is to drive the electric motor to provide an assist torque to reduce the steering torque exerted by the driver. What is more, it has the capability to improve the steering feel and to generate a response to the driver's torque commands. Even though it may be subject to external disturbances, it should work well. The steering shaft may vibrate since the electric motor amplifies the torque ripples. For the design of the EPS system, the most important item is the assistant strategy and the controller design. In the work in [6], the authors studied the controller design problem for EPS system using T-S fuzzy model approach. Since the velocity is involved in the model and the velocity is not a constant, the T-S fuzzy model is used to represent the nonlinear EPS system. Since the sensing may be subject to delays, the delay is also considered in the states. In [7], model development and control methodology of a new electric power steering system are presented. In [8], a novel electrohydraulic power steering system is described by a mathematical model and a nonlinear controller design for it. As the controller and the sensor may be subject to system faults, model-based fault detection and isolation for electric power steering system are presented in [9]. The system is firstly modeled and the fault is detected by using the established model. In order to overcome the uncertain factor, the development of an adaptive steering-control system is discussed in [10]. The designed controller is also implemented 


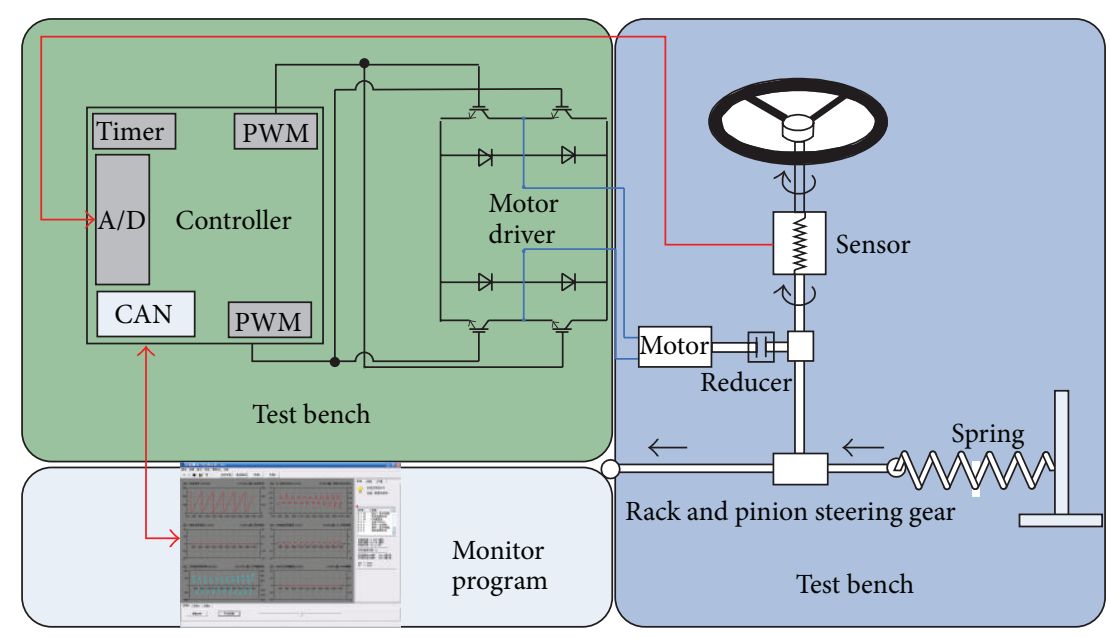

FIGURE 1: Overall view of the developed test rig.

and tested. The authors in [11] discussed an electric power steering system development. In [12], the authors discuss the application of an active disturbance rejection controller (ADRC) to an electrical power assist steering system with applications to automobiles. The robust controller design work is to reduce the steering torque exerted by a driver as well as to achieve good steering feel when the system is subject to external disturbances and unavoidable system uncertainties. Both the computer simulation and frequencydomain analyses show the robustness and compensation stability of the ADRC controlled system. It is well known that the torque ripple in an EPS system is unavoidable and it can be induced by a lot of issues such as the phase lag between steer angle and rack displacement and disturbances from road and sensor noise. This phenomenon becomes worse at the highspeed case. The authors in [13] investigate the sliding mode controller (SMC) design for an EPS system to not only reduce the torque ripple but also stabilize the dynamics of the EPS system. A nonlinear sliding mode observer (SMO) is also developed to estimate the unknown states. The simulation results verify that the designed nonlinear SMC and SMO strategies can reduce the torque ripple to achieve a better steering feeling. In [14], a new active disturbance rejection control is proposed for an electric power assist steering system, while in [15] genetic algorithm based PID controller is designed for the EPS system. In [16], we can see another robust controller design work for electric power steering systems. Controller design work for soft-disability remedy of the electric power steering system can be seen in [17]. Other works on this topic can be seen in [18-24].

However, in the literature, most of the results on the assistant strategy were obtained only by the simulation, which may be quite different from the real system. Furthermore, there is few work which has considered the problems encountered during the assistant such as the vibration and the steering feeling [25]. This lag between the theory and the real implementation motivates our work in this paper. In [26], the authors did some preliminary study on the experiment of EPS. In this work, we would extend the content a lot and add more details on the systems and experiments.
In this paper, we focus on the improvement of the antivibration ability $[27,28]$ of the EPS system by designing a new control algorithm. It is noted that a linear assistant algorithm can also reduce the steering wheel force. However, there are some problems, such as the dynamic characteristics and antivibration characteristics, which may affect the performance of the EPS system but cannot be revealed just by the simulation [29]. In the following sections, we will address the development of the EPS bench and develop the assistant strategy to suppress the vibration of the steering wheel. Finally, the control algorithm will be verified by an experiment.

\section{EPS Bench Test}

The overall view of the developed test rig is shown in Figure 1. We can see that the test platform of the EPS system consists of the following components:

(i) test bench;

(ii) EPS controller and motor driver;

(iii) steering sensor;

(iv) monitor program.

The test bench contains the steering wheel, steering column, steering pinion and the rack, and the assistant motor. The high level controller is the control law to be designed. And the low level controller is how to implement the control signal to the motor driver to derive the desired torque. The steering sensor is used to measure the steering angle to do the feedback control. In addition, a monitor program is developed to monitor the status of the test bench. In the following, the system components will be discussed in detail.

2.1. Test Bench. As shown in Figures 2 and 3, the EPS test bench includes rack and pinion steering gear, the simulation equipment of road force, steering wheel equipped torque, and angle sensor. A special spring offers the resistance force from road. The steering is assisted by an electric motor that acts directly on the rack bar through a pinion [29]. 


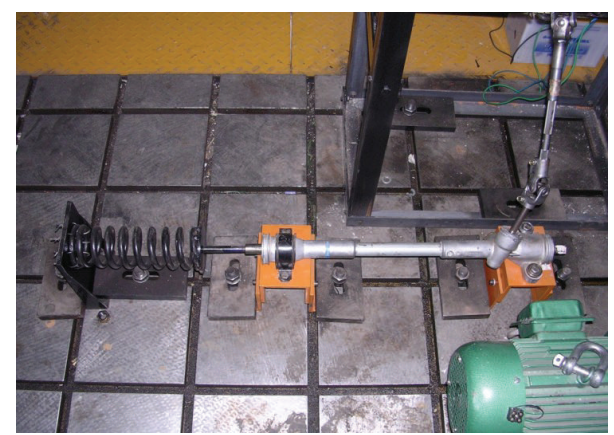

FIGURE 2: Rack and pinion steering gear in the test.

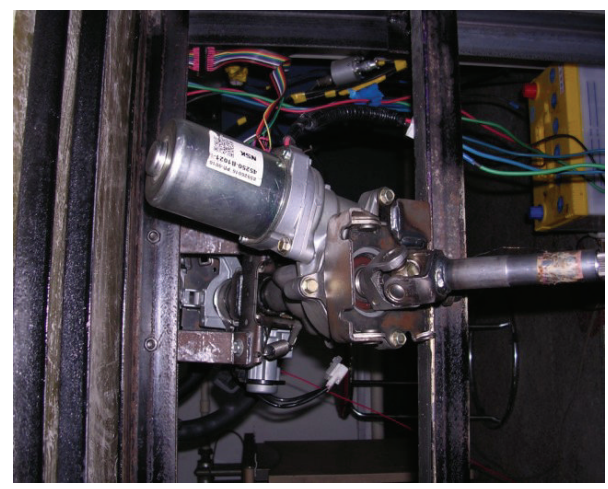

FIgURE 3: Assistant motor in the test.

2.2. EPS Controller and Motor Driver. A microcontroller (MC9S12D64, produced by Freescale Semiconductor, Inc.) is used as the main chip for EPS control module [30]. The model (see Figure 4: EPS controller) comprises four main parts:

(i) A/D converter, QEP, and photoelectric encoder;

(ii) 16-bit 2-channel PWM signals;

(iii) CAN port for communication;

(iv) sound and light alarm.

As shown in Figure 5, the principal part of the motor driver is composed of four MOSFETs (metal-oxide semiconductor field-effect transistors), which make up H-bridge for four-quadrant operation ambipolar with a current sensor in reversible circuit. We use IR2130, produced by International Rectifier, to drive H-bridge.

2.3. Monitor Program. To monitor the status parameters and analyze the collected data, we developed monitor program and hardware driver as shown in Figure 6. With the data we get from CAN bus, we can observe the parameter of controller on PC and can debug the algorithm easier. The PC use USB to get data, whereas the ECU send data through CAN port, so we develop a CAN card to transfer the data (see Figure 7). All application programs and hardware driver programming are based on Microsoft Visual Studio 2005.

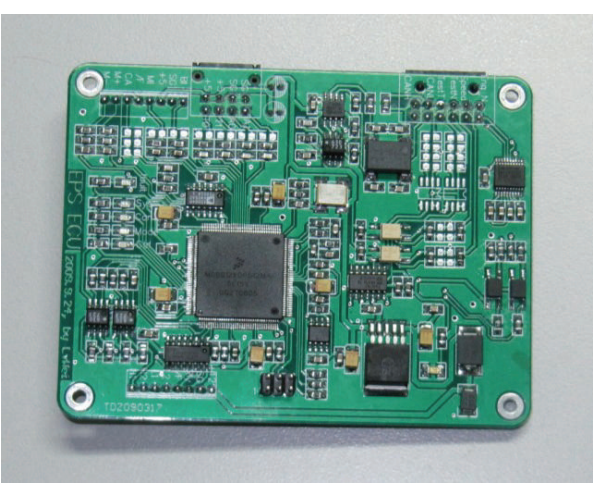

FIGURE 4: EPS controller for the test.

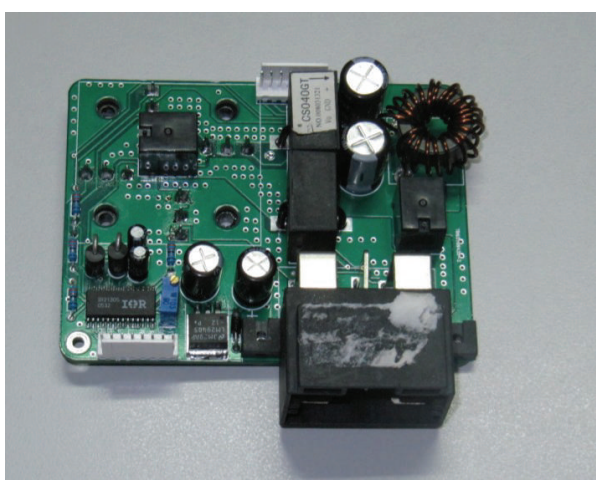

FIgURE 5: Motor driver for the test.

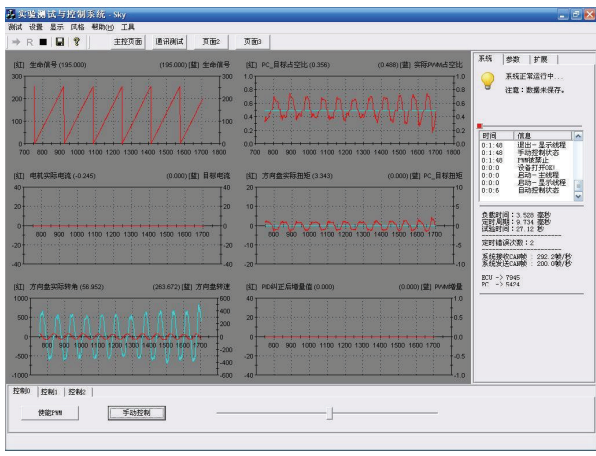

FIgURE 6: Monitor program on PC in the test.

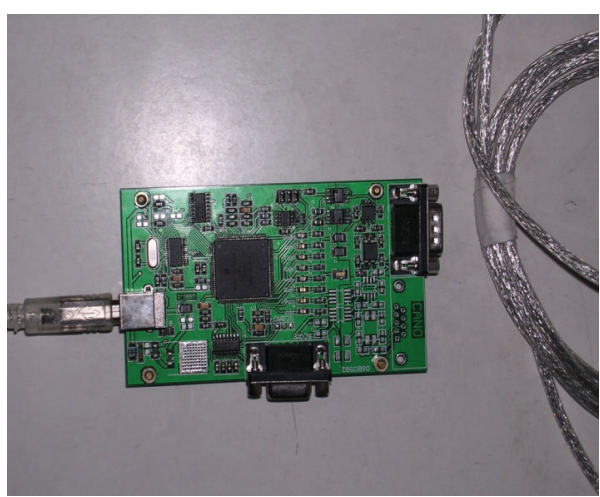

FIGURE 7: CAN card in the test. 


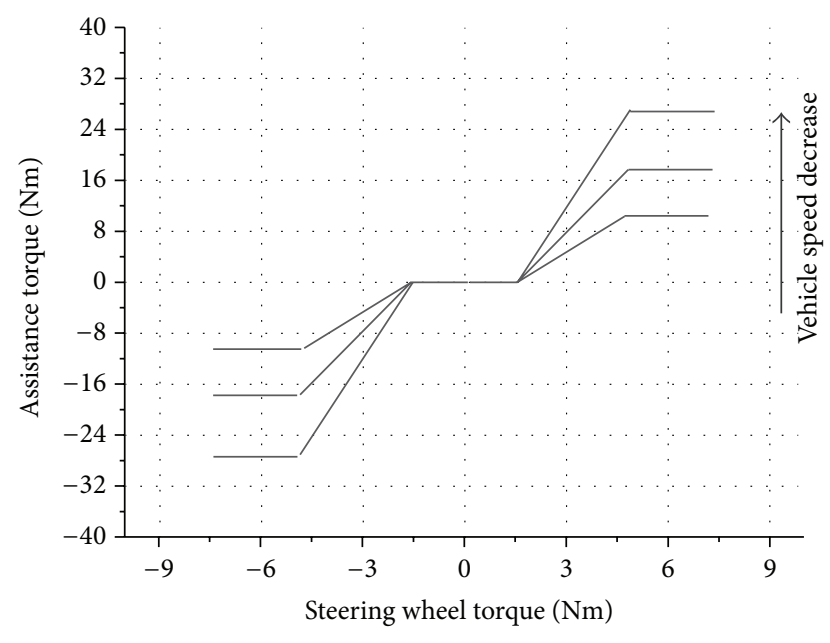

FIGURE 8: Linear assistant characteristics in the test.

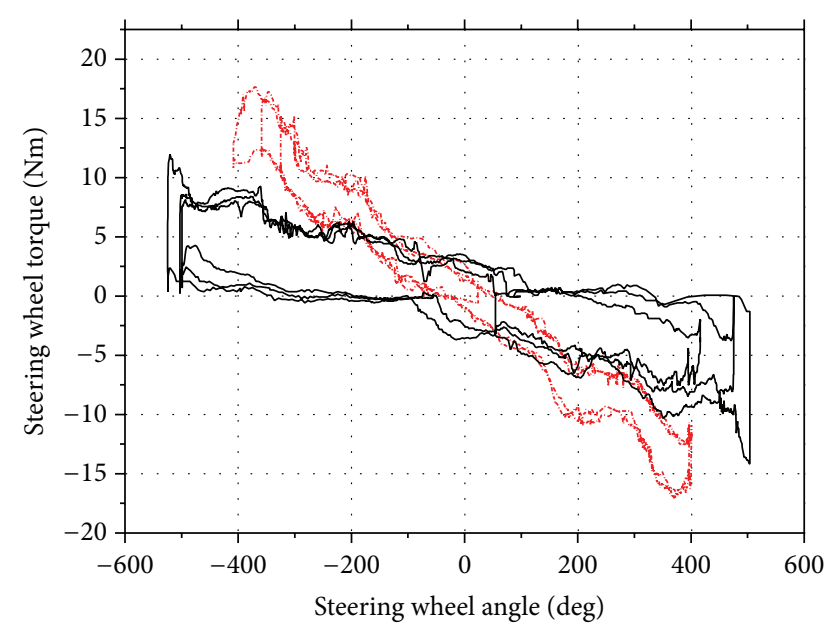

FIGURE 9: Steering wheel torque in the basic assist strategy in the test.

\section{Basic Assist Algorithm}

After the development of the experiment platform, we test the assistant strategy shown in Figure 8. We obtained the strategy from the experimental data of a hydraulic steering system [2]. It infers from the assistant characteristics that the assistant torque is zero when the steering wheel torque is small such as in the range of $[-1,1] \mathrm{Nm}$. If the vehicle velocity is small, the assistant torque is large to help the driver to achieve the desired steering angle quickly. However, if the vehicle speed is large, the assistant torque is relatively small to keep the safety.

In the experiment, the steering wheel is chosen as a sinewave angle input; the amplitude is $\pm 540^{\circ}$. The steering wheel torque curve is shown in Figure 9. The dash-dotted curve is the steering wheel torque without assist. The maximal torque is larger than $15 \mathrm{Nm}$. After adding the necessary torque to system according to Figure 8, it does decrease the steering torque [3]. The maximal torque is only above $10 \mathrm{Nm}$. However, during the experiment, the system creates harsh steering feel when applying the assist characteristics. It is

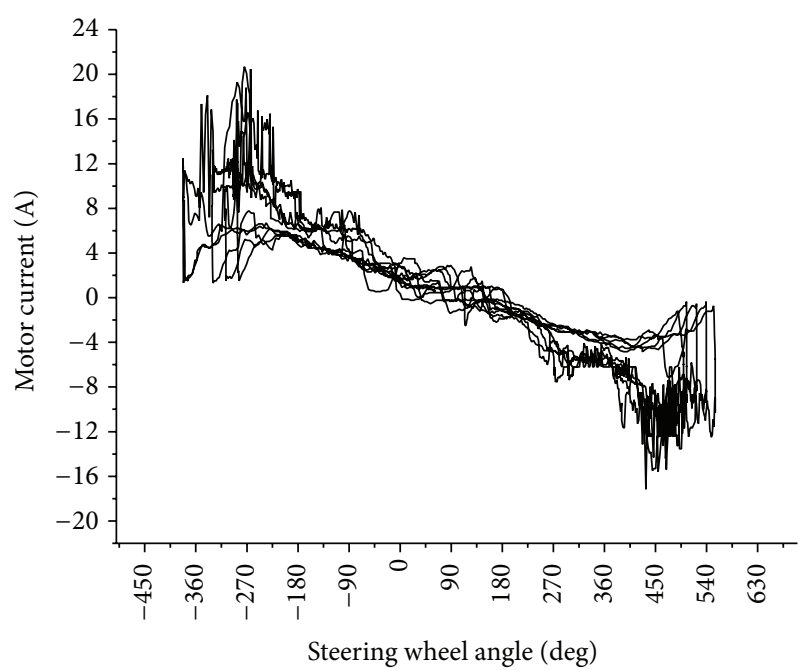

FIGURE 10: Motor current in the test.

certified by the current of DC motor as shown in Figure 10 in which the current fluctuates quickly especially when the steering angle is around $450^{\circ}$. The fluctuation of the current in Figure 10 would result to the vibration of hand wheel seriously.

\section{Antivibration Controller Design}

In this work, we will introduce the antivibration controller design method which is originally from [31]. By identifying the system parameters, the controller is designed and implemented in the EPS system.

The effects of the vibration shown in Figure 10 will result in the driver's uncomfortable feeling. More seriously, with the vibration increase, it will make the steering wheel lose control. The steering process must be limited to a steadystate maneuver. Assuming the steering wheel is locked, the relationship between motor torque and reaction torque from road can be expressed as

$$
J_{T} \ddot{\theta}_{P}+\zeta \dot{\theta}_{P}+K_{S} \theta_{P}=T_{M}+T_{R}+T_{H},
$$

where $J_{T}$ is the total inertias and $\zeta$ is the effective damping coefficient. $K_{S}$ represents the stiffness of the torsion bar in the torque sensor. $T_{R}, T_{M}$, and $T_{H}$ are the external torque at the pinion axis, the motor output torque to assist the steering, and the torque needed to hold the steering wheel. $\theta_{P}$ represents pinion angle.

The output torque of DC motor is

$$
T_{M}=K_{M} C_{T}\left(I_{M}-\frac{K_{E} K_{M} \dot{\theta}_{P}}{R}\right) .
$$

Since the motor current is proportional to the torque sensor output, $I_{M}$ can be expressed as follows:

$$
I_{M}=-\frac{K_{P} \theta_{P}}{R} .
$$


$K_{P}$ is the combination of the torque sensor stiffness and output gain. The disturbance from the external torque applied at the rack to the torque needed to hold the steering wheel $\left(T_{H}\right)$ is equal to [31]

$$
T_{H}=K_{S} \theta_{P},
$$

where $K_{M}, C_{T}$, and $I_{M}$ are the gear box gear ratio, torque constant, and the armature winding current. $K_{E}, R$, and $K_{a}$ are the motor back electromagnetic force constant, armature winding resistance, and the assist ratio. Substituting (2), (3), and (4) into (1), we get

$$
J_{T} \ddot{\theta}_{P}+\left(\zeta+\frac{K_{M}^{2} K_{E} C_{T}}{R}\right) \dot{\theta}_{P}+\left(K_{S}-\frac{K_{M} C_{T} K_{P}}{R}\right) \theta_{P}=T_{R} .
$$

The natural frequency and damping ratio of the second-order system are equal to

$$
\omega_{n}=\sqrt{\frac{K}{J_{T}}}, \quad \varsigma=\frac{B}{2 \sqrt{J_{T} K}},
$$

where

$$
\begin{gathered}
K=K_{s}-\frac{K_{M} C_{T} K_{P}}{R}, \\
B=\zeta+\frac{K_{M}^{2} K_{E} C_{T}}{R} .
\end{gathered}
$$

Please note that the natural frequency increases with the proportional gain and the damping ratio decreases when the proportional gain increases. Owing to higher gain that is needed for higher steering assistant, the damping ratio is relatively lower, which decreases the performance of antivibration [25]. As a result, a pure proportional control does not fit in this system.

To solve the dilemma faced by the proportional control, we add a derivative constant between steering wheel torque and motor current. The equation is

$$
I_{M}=\frac{-K_{p} \theta_{p}-K_{d} \dot{\theta}_{p}}{R} .
$$

Substituting the above function into (1), we get

$$
\begin{aligned}
J_{T} \ddot{\theta}_{P} & +\left(\zeta+\frac{K_{M}^{2} K_{E} C_{T}}{R}+K_{M} C_{T} K_{d}\right) \dot{\theta}_{P} \\
& +\left(K_{S}-\frac{K_{M} C_{T} K_{P}}{R}\right) \theta_{P}=T_{R} .
\end{aligned}
$$

By choosing an appropriate proportional gain $\left(K_{p}\right)$, we can achieve the desired steering assistance level, and the damping ratio can also be controlled by adjusting derivative gain $\left(K_{d}\right)$. Figure 11 shows the steering wheel torque after adjustment. Apparently, it has lower hash steering feel than basic assistant as shown in Figure 12.

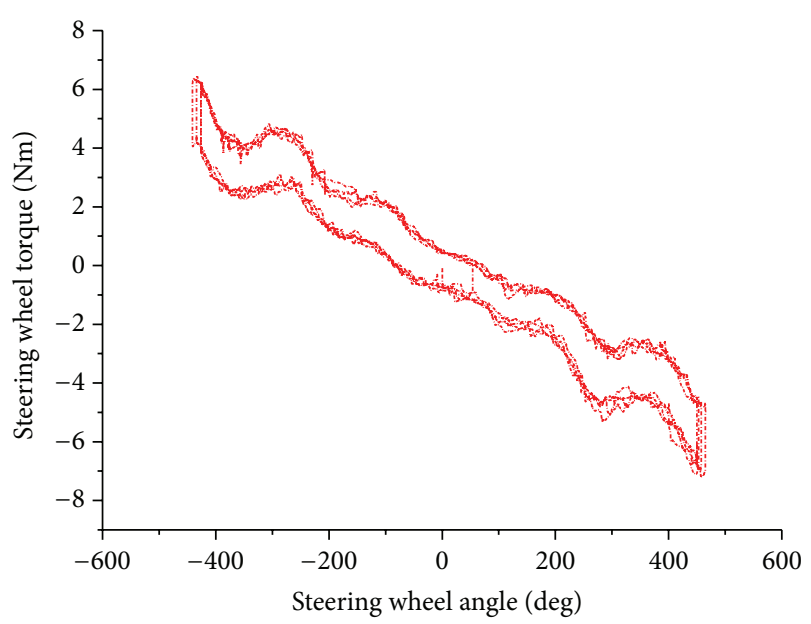

FIGURE 11: The relationship between the steering wheel torque and the steering wheel angle in the antivibration control.

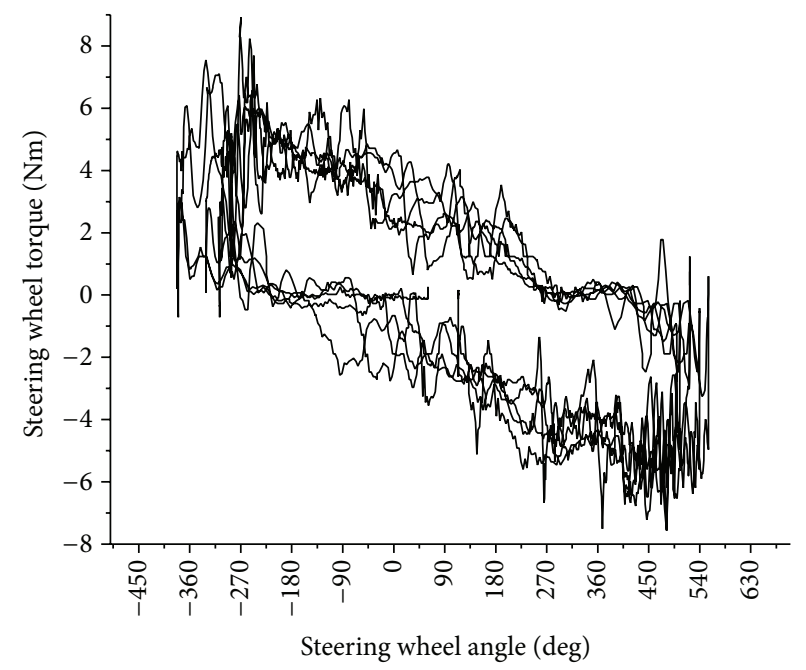

FIGURE 12: The relationship between the steering wheel torque and the steering wheel angle in the basic control.

Remark 1. In the work, the possible nonlinearities and the uncertainties are not incorporated. If the nonlinearities and the uncertainties should be considered, more advanced methods can be employed such as the recent excellent works [3239]. For the nonlinear systems, the T-S fuzzy techniques can be used. For the uncertainties, the robust control can be used.

\section{Conclusion}

In this paper, we have focused on the antivibration controller design problem for EPS systems. In order to deal with the controller design we have built up bench test for EPS. Firstly, the basic assistant strategy of EPS system, based on hydraulic steering systems, is verified. From the experimental study, we found the dilemma faced by assistant gain and performance of antivibration control. To reduce the vibration, by analyzing the mathematic model of EPS, a new strategy is designed and 
tested on rig. The testing data validates that the performance of antivibration is better than the basic control strategy. In the future research, we will focus more on the advanced controller design such as the robust $H_{\infty}$ control and network control; see [40-48] and the references therein. What is more, the developed system will go to the market.

\section{Conflict of Interests}

The authors declare that there is no conflict of interests regarding the publication of this paper.

\section{Acknowledgment}

The research leading to these results has received funding from the Polish-Norwegian Research Programme operated by the National Centre for Research and 24 Development under the Norwegian Financial Mechanism 2009-2014 in the frame of Project Contract no. Pol-Nor/200957/47/2013.

\section{References}

[1] Y. Shimizu and T. Kawai, "Development of electric power steering," SAE Paper 910014.

[2] Y. Kozaki, G. Hirose, S. Sekiya, and Y. Miyaur, "Electric Power Steering (EPS)," Motion \& Control, NSK Technical Journal, vol. 6, article 9, 1999.

[3] J.-H. Kim and J.-B. Song, "Control logic for an electric power steering system using assist motor," Mechatronics, vol. 12, no. 3, pp. 447-459, 2002.

[4] J. S. Chen, "Control of electric power steering systems," SAE Technical Papers, 1998.

[5] B. I. Pryjmak, "Simulation of electric power steering armature inertia effects on vehicle system handling response using bondgraph technology," SAE Technical Papers 851639,1985,94:5.10175.1031, 1985.

[6] X. Li, X.-P. Zhao, and J. Chen, "Controller design for electric power steering system using T-S fuzzy model approach," International Journal of Automation and Computing, vol. 6, no. 2, pp. 198-203, 2009.

[7] J. Song, K. Boo, H. S. Kim, J. Lee, and S. Hong, "Model development and control methodology of a new electric power steering system," Proceedings of the Institution of Mechanical Engineers D: Journal of Automobile Engineering, vol. 218, no. 9, pp. 967-975, 2004.

[8] W. Kemmetmüller, S. Müller, and A. Kugi, "Mathematical modeling and nonlinear controller design for a novel electrohydraulic power-steering system," IEEE/ASME Transactions on Mechatronics, vol. 12, no. 1, pp. 85-97, 2007.

[9] J. Lee, H. Lee, J. Kim, and J. Jeong, "Model-based fault detection and isolation for electric power steering system," in Proceedings of the International Conference on Control, Automation and Systems (ICCAS '07), pp. 2369-2374, October 2007.

[10] A. E. Cetin, M. A. Adli, D. Erol Barkana, and H. Kucuk, "Implementation and development of an adaptive steering-control system," IEEE Transactions on Vehicular Technology, vol. 59, no. 1, pp. $75-83,2010$.
[11] W. Ren, H. Chen, and J. Song, "Model-based development for an electric power steering system," Proceedings of the Institution of Mechanical Engineers C: Journal of Mechanical Engineering Science, vol. 222, no. 7, pp. 1265-1269, 2008.

[12] L. Dong, P. Kandula, Z. Gao, and D. Wang, "On a robust control system design for an electric power assist steering system," in Proceedings of the American Control Conference (ACC '10), pp. 5356-5361, July 2010.

[13] X. Li, X.-P. Zhao, and J. Chen, "Sliding mode control for torque ripple reduction of an electric power steering system based on a reference model," Proceedings of the Institution of Mechanical Engineers D: Journal of Automobile Engineering, vol. 222, no. 12, pp. 2283-2290, 2008.

[14] L. Dong, P. Kandula, Z. Gao, and D. Wang, "Active disturbance rejection control for an electric power assist steering system," International Journal of Intelligent Control and System, vol. 15, pp. 18-24, 2010.

[15] M. K. Hassan, N. A. M. Azubir, H. M. I. Nizam, S. F. Toha, and B. S. K. K. Ibrahim, "Optimal design of Electric Power Assisted Steering system (EPAS) using GA-PID method," Procedia Engineering, vol. 41, pp. 614-621, 2012.

[16] G. Chen, H. Chen, and L. Chen, "The method descending the order of the multidisciplinary robust control model for electric power steering systems," in Proceedings of the International Conference on Digital Manufacturing and Automation (ICDMA '10), pp. 725-728, December 2010.

[17] X. Li, X. P. Zhao, J. Chen, and J. L. Men, "Controller design for soft-disability remedy of the electric power steering system," International Journal of Automotive Technology, vol. 10, no. 4, pp. 497-503, 2009.

[18] X. Zhao, X. Shi, J. Chen, and X. Li, "Dynamic correction of the steering-characteristic curve and application to an EPS control system," International Journal of Automotive Technology, vol. 12, no. 2, pp. 243-249, 2011.

[19] Z. Jianjun, Z. Man, C. Min'gang, L. Su, and L. Bin, "Automatic navigation system for electric power vehicles with EPS," in Proceedings of the IEEE Vehicle Power and Propulsion Conference (VPPC '08), September 2008.

[20] Y. H. Liu and X. W. Ji, "Matching strategy of electric power steering assistant characters based on the vehicle inherent road feel," Proceedings of the Institution of Mechanical Engineers D: Journal of Automobile Engineering, vol. 225, no. 11, pp. 1481-1491, 2011.

[21] H. Lee, "Analysis of model-based sensor fault diagnosis with application to a motor-driven power steering system," Proceedings of the Institution of Mechanical Engineers D: Journal of Automobile Engineering, vol. 225, no. 10, pp. 1317-1333, 2011.

[22] Q. Li, Z. Duan, G. Shi, and J. Wei, "Study on the impact of variable gear ratio on the EPS damping control," in Proceedings of the International Conference on Computer, Mechatronics, Control and Electronic Engineering (CMCE '10), pp. 604-607, August 2010.

[23] A. Marouf, M. Djemai, C. Sentouh, and P. Pudlo, "A new control strategy of an electric-power-assisted steering system," IEEE Transactions on Vehicular Technology, vol. 61, no. 8, pp. 35743589, 2012.

[24] S. H. Kim, M. C. Shin, and C. N. Chu, "Development of EHPS motor speed map using HILS system," IEEE Transactions on Vehicular Technology, vol. 62, no. 4, pp. 1553-1567, 2013.

[25] Y. Shimizu and Y. Oniwa, "Control for moment of motor inertia on EPS," SAE Technical Papers, 2006. 
[26] W. Zhaojian, G. Konghui, Z. Jianwei, D. Haitao, and C. Shuang, "Experimental study on anti-vibration of EPS," in Proceedings of the International Conference on Computer, Mechatronics, Control and Electronic Engineering (CMCE '10), pp. 292-295, August 2010.

[27] P. Xu, B. Bernardo, and K. Tan, "Optimal mounting design for cab vibration isolation," International Journal of Vehicle Design, vol. 57, no. 2-3, pp. 292-304, 2011.

[28] P. Xu, G. Peticca, and D. Wong, "A technique for developing a high accuracy durability test for a light truck on a six degreeof-freedom road test simulator," International Journal of Vehicle Design, vol. 47, no. 1-4, pp. 290-304, 2008.

[29] Z. Wang, Experimental study on the assist compensation strategy of the control of electric power steering system [M.S. thesis], Jilin University, 2008.

[30] MC9S12DJ64 Device User Guide-V 01.17, Motorola, 2004.

[31] J. S. Chen, "Control of electric power steering systems," SAE Technical Papers, 1998.

[32] M. Chadli, H. R. Karimi, and P. Shi, "On stability and stabilization of singular uncertain Takagi-Sugeno fuzzy systems," Journal of the Franklin Institute, vol. 351, pp. 1453-1463, 2014.

[33] M. Chadli and H. R. Karimi, "Robust observer design for unknown inputs Takagi-sugeno models," IEEE Transactions on Fuzzy Systems, vol. 21, no. 1, pp. 158-164, 2013.

[34] H. Zhang and J. Wang, "Combined feedback-feedforward tracking control for networked control systems with probabilistic delays," Journal of the Franklin Institute, vol. 351, no. 6, pp. 34773489, 2014.

[35] H. Zhang, X. Zhang, and J. Wang, "Robust gain-scheduling energy-to-peak control of vehicle lateral dynamics stabilisation," Vehicle System Dynamics, vol. 52, no. 3, pp. 309-340, 2014.

[36] H. Zhang, Y. Shi, and J. Wang, "On energy-to-peak filtering for nonuniformly sampled nonlinear systems: a Markovian jump system approach," IEEE Transactions on Fuzzy Systems, vol. 22, no. 1, pp. 212-222, 2014.

[37] M. Chadli, S. Aouaouda, H. R. Karimi, and P. Shi, "Robust fault tolerant tracking controller design for a VTOL aircraft," Journal of the Franklin Institute, vol. 350, no. 9, pp. 2627-2645, 2013.

[38] M. Chadli and T. M. Guerra, "LMI solution for robust static output feedback control of discrete Takagi-sugeno fuzzy models," IEEE Transactions on Fuzzy Systems, vol. 20, no. 6, pp. 1160-1165, 2012.

[39] M. Chadli, A. Abdo, and S. X. Ding, "H-/ $H_{\infty}$ fault detection filter design for discrete-time Takagi-Sugeno fuzzy system," Automatica, vol. 49, no. 7, pp. 1996-2005, 2013.

[40] H. Zhang, J. Wang, and Yang Shi, "Robust $H_{\infty}$ sliding-mode control for Markovian jump systems subject to intermittent observations and partially known transition probabilities," Systems \& Control Letters, vol. 62, pp. 1114-1124, 2013.

[41] H. Zhang, Y. Shi, and J. Wang, "Observer-based tracking controller design for networked predictive control systems with uncertain Markov delays," International Journal of Control, vol. 86, pp. 1824-1836, 2013.

[42] C. Lin, Q. G. Wang, T. H. Lee, and Y. He, "Design of observerbased $H_{\infty}$ control for fuzzy time-delay systems," IEEE Transactions on Fuzzy Systems, vol. 16, no. 2, pp. 534-543, 2008.

[43] H. Zhang, Y. Shi, and M. Liu, " $H_{\infty}$ step tracking control for networked discrete-time nonlinear systems with integral and predictive actions," IEEE Transactions on Industrial Informatics, vol. 9, no. 1, pp. 337-345, 2013.
[44] Z. Shuai, H. Zhang, J. Wang, J. Li, and M. Ouyang, "Lateral motion control for four-wheel-independent-drive electric vehicles using optimal torque allocation and dynamic message priority scheduling," Control Engineering Practice, vol. 24, pp. 55-66, 2014.

[45] J. Wang, Q. Wang, C. Song, L. Chu, and Y. Wang, "Coordinated control of differential drive assisted steering system with vehicle stability enhancement system," in Proceedings of the IEEE Intelligent Vehicles Symposium (IV '11), pp. 1148-1155, June 2011.

[46] H. Zhang, Y. Shi, and A. S. Mehr, "Robust weighted $H_{\infty}$; filtering for networked systems with intermittent measurements of multiple sensors," International Journal of Adaptive Control and Signal Processing, vol. 25, no. 4, pp. 313-330, 2011.

[47] C. Dannöhla, S. Müllerb, and H. Ulbrichc, " $H_{\infty}$-control of a rack-assisted electric power steering system," Vehicle System Dynamics, vol. 50, pp. 527-544, 2012.

[48] H. Zhang, Y. Shi, and A. S. Mehr, "Robust static output feedback control and remote PID design for networked motor systems," IEEE Transactions on Industrial Electronics, vol. 58, no. 12, pp. 5396-5405, 2011. 


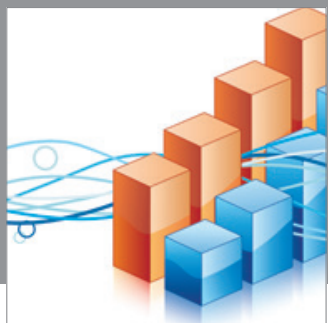

Advances in

Operations Research

mansans

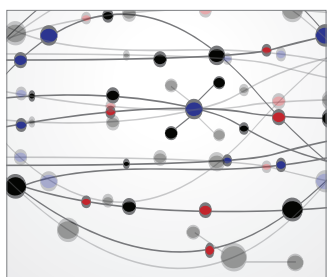

The Scientific World Journal
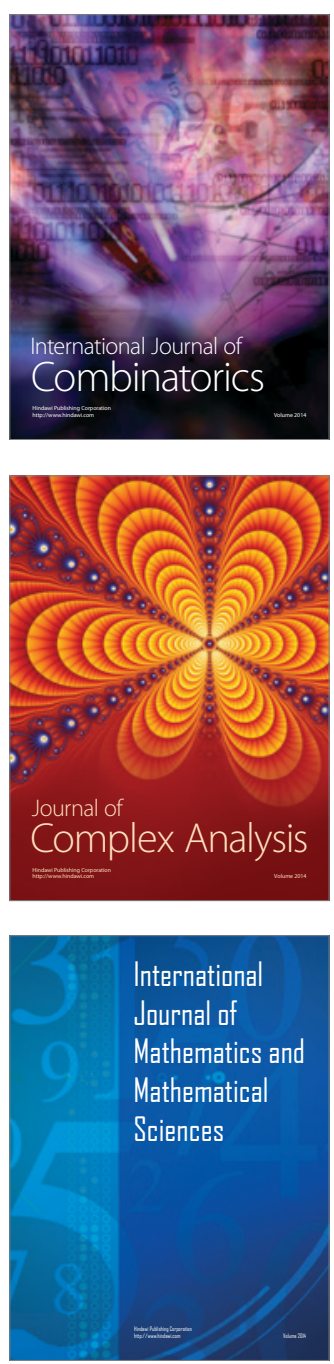
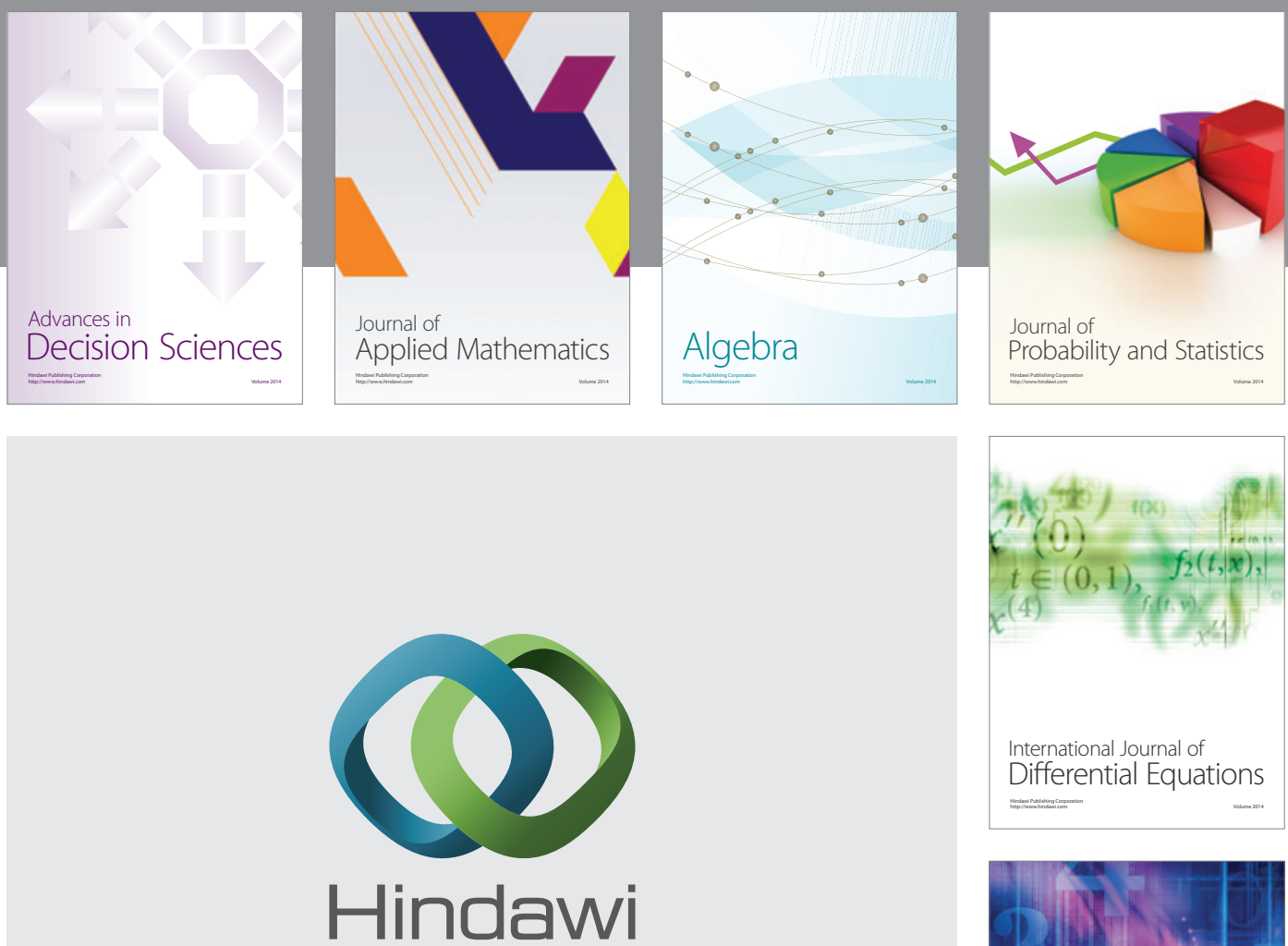

Submit your manuscripts at http://www.hindawi.com
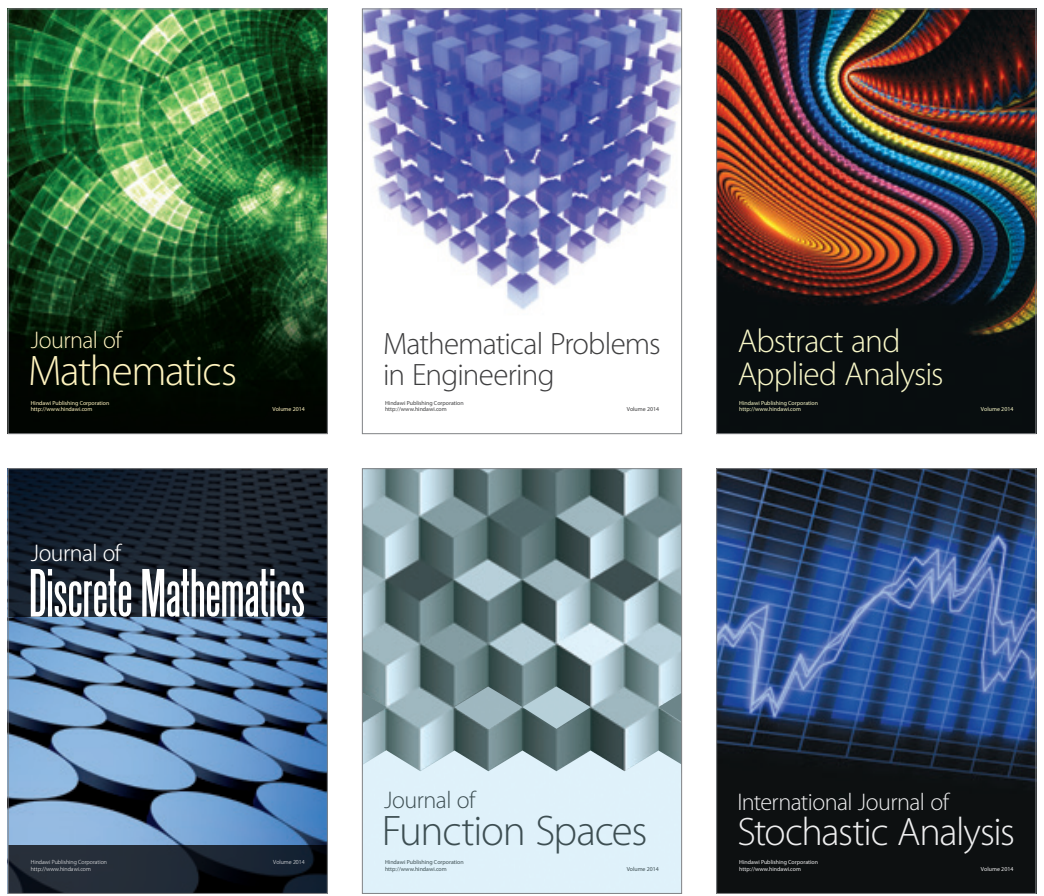

Journal of

Function Spaces

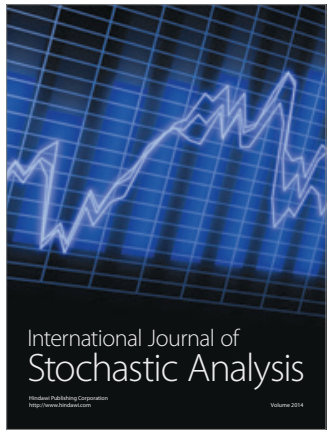

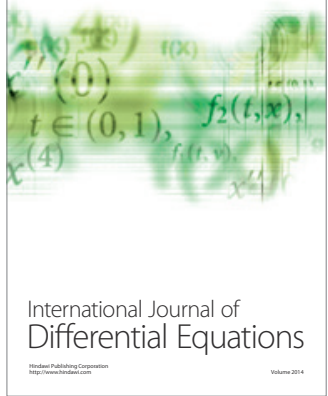
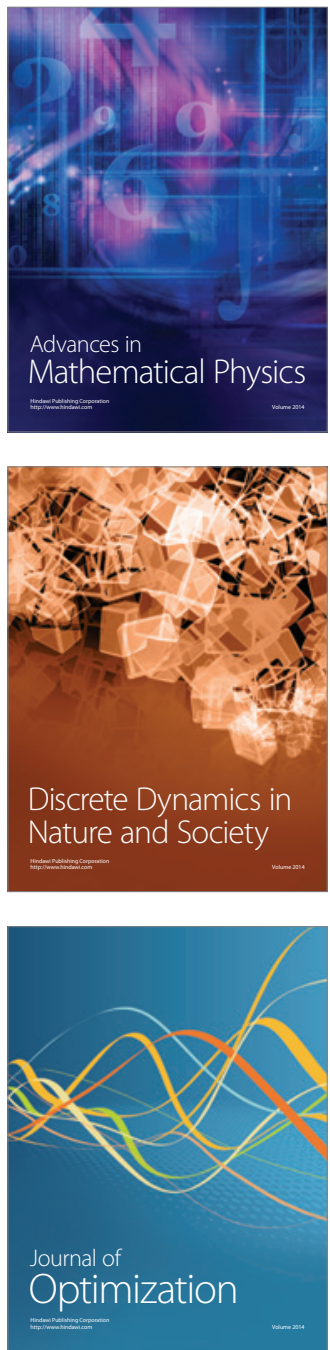